Prepared in cooperation with the New Hampshire Department of Environmental Services

\title{
Per- and Polyfluoroalkyl Substances (PFAS) in New Hampshire Soils and Biosolids
}

\section{What Are PFAS?}

Per- and polyfluoroalkyl substances (PFAS) are a diverse class of thousands of synthetic compounds that are used for a variety of industrial purposes and that can be found in consumer products such as food packaging, nonstick cooking surfaces, water- and stainresistant fabrics, cosmetics, and waterrepellent clothing (fig. 1; U.S. Environmental Protection Agency, 2018; Agency for Toxic Substances and Disease Registry, 2020). Many PFAS are frequently detected in the environment, including in soil, water, and air (fig. 2). Although some PFAS have been produced and used in products since the 1940 s, they have only recently come under intense scrutiny for their potential link to adverse human health effects, including decreased response to vaccines, thyroid disease, and decreased birth weight (U.S. Environmental Protection Agency, 2018; Agency for Toxic Substances and Disease Registry, 2020).
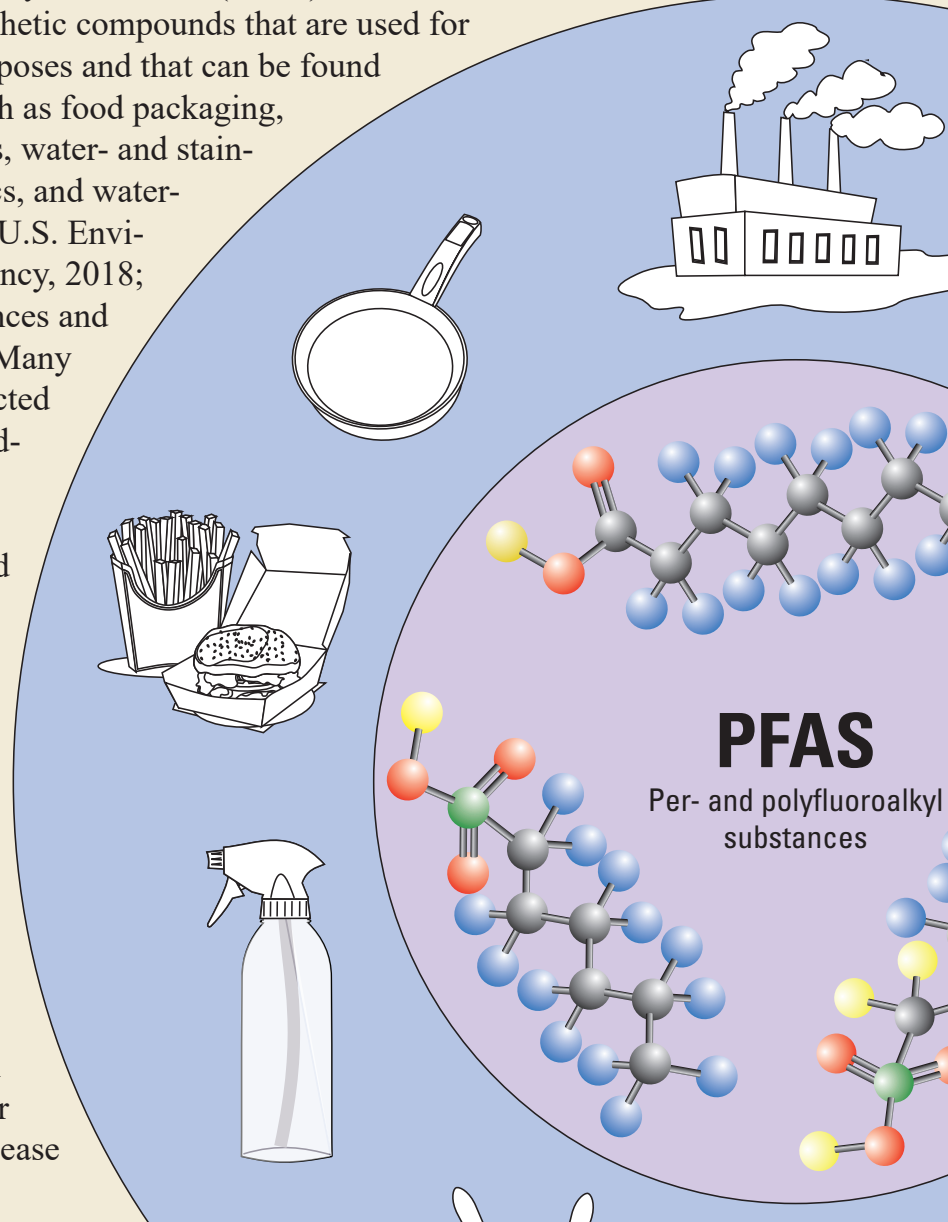


\section{What Are We Working On?}

One gap in our understanding of PFAS in the environment concerns PFAS concentrations in soils and biosolids. Biosolids are processed solids from wastewater treatment plants that are often applied to the land surface to provide organic matter and nutrients, such as nitrogen and phosphorous. Because biosolids can contain organic compounds such as PFAS, land-application of biosolids may introduce PFAS to the environment. There are also gaps in our understanding of how PFAS travel from soils to groundwater, which is a source of drinking water in many parts of the United States, including New Hampshire. The U.S. Geological Survey is working with the New Hampshire Department of Environmental Services to do the following:

1. Characterize concentrations of PFAS in shallow soil throughout New Hampshire (figs. 3 and 4), and quantify PFAS concentrations in selected biosolids samples.

2. Conduct laboratory experiments to understand how PFAS move from soil and biosolids to water under a variety of conditions.

3. Investigate PFAS groundwater and soil concentrations at one or two selected sites in New Hampshire to compare field observations with soil-to-water transport properties measured in the laboratory.

\section{What Is the Benefit of This Work?}

The findings will help us understand the occurrence of PFAS in New Hampshire surface soils and biosolids and evaluate factors that affect the movement of PFAS in the environment. Officials in State and Federal agencies can use these findings when considering how to best protect human and ecosystem health.

\section{References Cited}

Agency for Toxic Substances and Disease Registry, [2020], Per- and polyfluoroalkyl substances (PFAS) and your health: Agency for Toxic Substances and Disease Registry web page, accessed March 5, 2021, at https:/www.atsdr.cdc.gov/pfas/ index.html.

\section{U.S. Environmental Protection Agency, [2018], PFAS-} What you need to know: U.S. Environmental Protection Agency infographic, 2 p., accessed March 5, 2021, at https:/www.epa.gov/sites/production/files/2018-03/ documents/pfasv15_2pg_0.pdf.

By Andrea K. Tokranov, ${ }^{1}$ Kate Emma A. Schlosser, ${ }^{2}$ Jeffrey M. Marts, ${ }^{2}$ Anthony F. Drouin, ${ }^{2}$ Leah M. Santangelo, ${ }^{1}$ and Sydney M. Welch ${ }^{1}$

${ }^{1}$ U.S. Geological Survey.

${ }^{2}$ New Hampshire Department of Environmental Services.

For more information, contact

Director, New England Water Science Center

U.S. Geological Survey

dc_nweng@usgs.gov

https://www.usgs.gov/centers/new-england-water

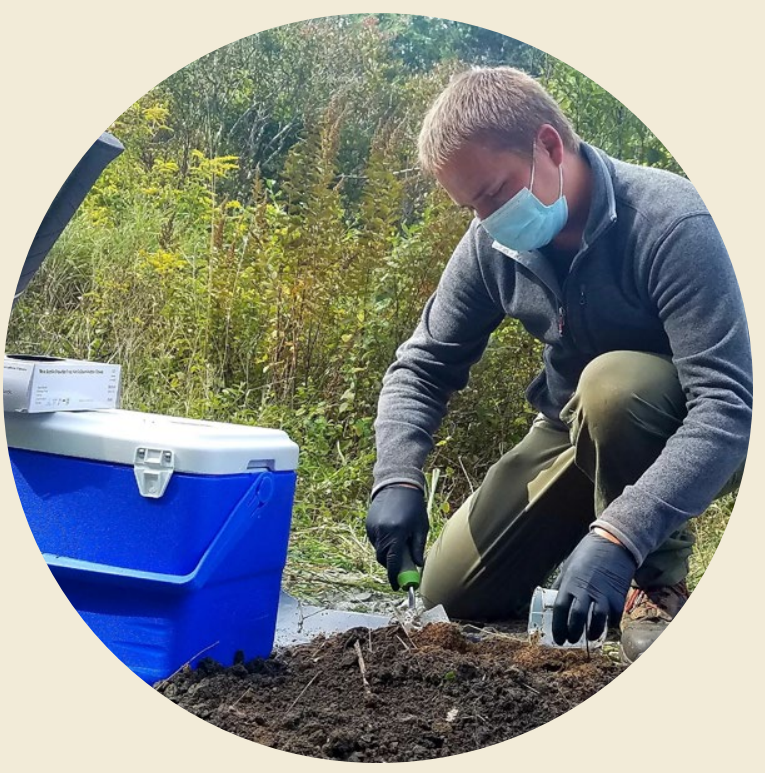

Figure 2. U.S. Geological Survey hydrologic technician collects a sample of soil affected by per- and polyfluoroalkyl substances (PFAS).

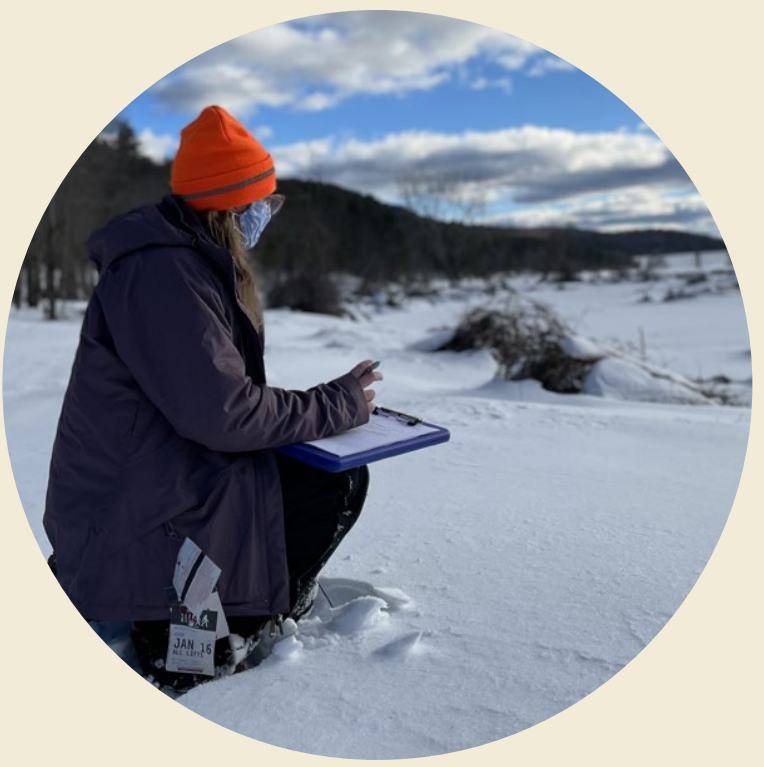

Figure 3. U.S. Geological Survey physical scientist records observations while inspecting a future soil sampling site.

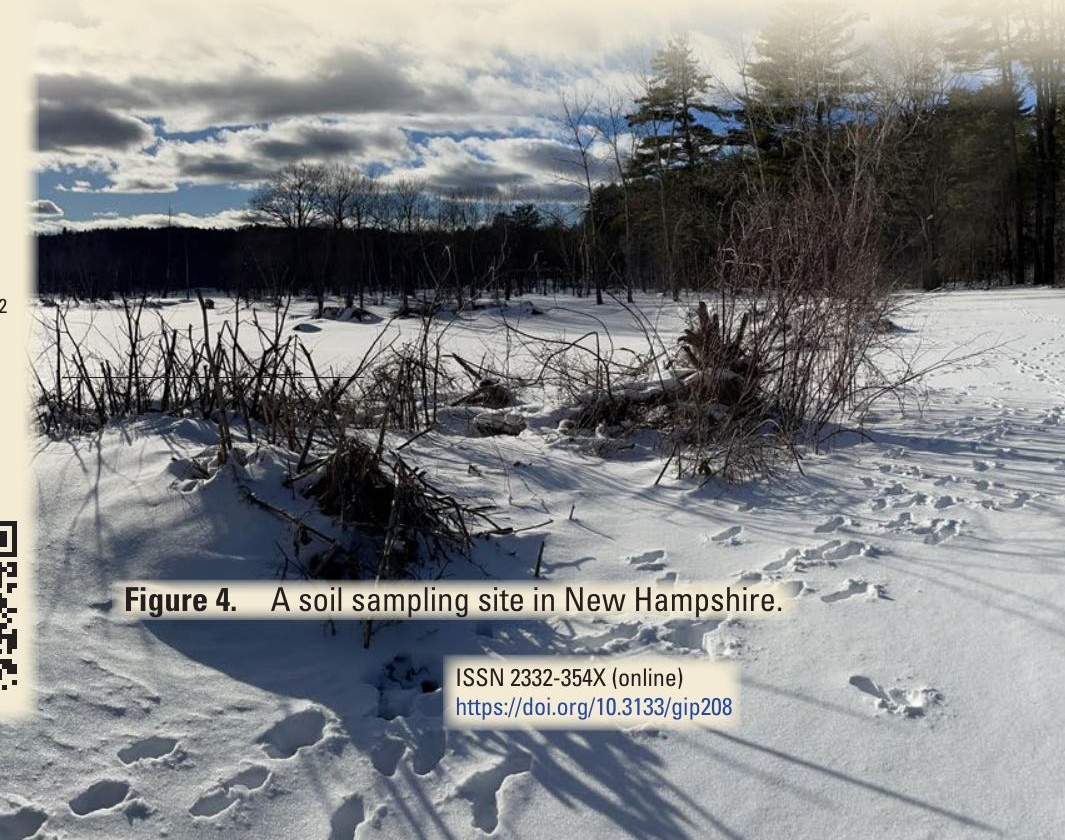

